\title{
Assessing the influence of Mathematics in Teaching and Learning Physics Subject in Secondary Schools in Tanzania
}

\author{
Sospeter Shikulu Malaki
}

Department of Information and Communication Technology, Tanzania Public Service College, East Africa.

\begin{abstract}
Learning Mathematics is a key fundamental in every education system that aims to prepare its citizens for a productive life in the $21^{\text {st }}$ century. As a nation, the development of a highly-skilled and well-educated manpower is critical to support an innovation and technology-driven economy. A strong grounding in Mathematics and a talent pool in Mathematics are essential to support the wide range of value-added economic activities and innovations. In this vein, a study intended to assess the influence of Mathematics in teaching and learning Physics, a case study of secondary education. A study was guided by two specific objectives; to determine the applications of Mathematics in Physics and to investigate the relationship between Mathematics and Physics. The qualitative and quantitative approaches were used in getting categorical and numerical data in line with the triangulation research design employed. Students and science teachers were targeted in the collection of data which made a total of 60 participants. The questionnaire, observation and documentary review were key devices used in data collection processes. The collected data were analyzed by using SPSS and the research findings revealed that there is statistically very strong positive relationship between Mathematics and Physics. . In other words, the influence of Mathematics in Physics subject is enormous to the extent that students are encouraged not to drop Mathematics in their early classes. This will assist to increase number of Tanzanian engineers and geologists in various sectors for extracting our natural resources.
\end{abstract}

\section{Key words: Mathematics, Physics, Teaching, Learning and Science}

\subsection{Introduction}

Learning Mathematics is a key fundamental in every education system that aims to prepare its citizens for a productive life in the $21^{\text {st }}$ century. As a nation, the development of a highly-skilled and well-educated manpower is critical to support an innovation- and technology-driven economy. A strong grounding in Mathematics and a talent pool in Mathematics are essential to support the wide range of value-added economic activities and innovations. Many countries are paying attention to the quality of their Mathematics education. The growing interest in trends in international Mathematics and science study (TIMSS) and programme for international student assessment (PISA) speaks of the global interest and importance placed on Mathematics education.

At the individual level, Mathematics underpins many aspects of our everyday activities, from making sense of information in the newspaper to making informed decisions about personal finances. It supports learning in many fields of study, whether it is in the sciences or in business. A good understanding of basic Mathematics is essential wherever calculations, measurements, graphical interpretations and statistical analysis are necessary. The learning of Mathematics also provides an excellent vehicle to train the mind, and to develop the capacity to think logically, abstractly, critically and creatively. These are important $21^{\text {st }}$ century competencies that we must imbue in our students, so that they can lead a productive life and be lifelong learners (MoE, 2012).

\subsection{Philosophical background}


This study investigated the influence of Mathematics subject in teaching and learning Physics in secondary schools in Tanzania, case study of Mtwara municipality. This section speculates the views of various philosophers about the influence of Mathematics in Physics subject.

Newton applied his binomial theorem to infinite series and from there developed Calculus, discovered the Binomial Theorem, and formulated a theory of universal gravitation a revolutionary new form of Mathematics. Newton has been regarded for almost 300 years as the founding exemplar of modern physical science, his achievements in experimental investigation being as innovative as these in Mathematical research. Most modern historians believe that Newton and Leibniz developed Calculus independently, although with very different notations. Occasionally it has been suggested that Newton published almost nothing about it until 1693, and did not give a full account until 1704. Newton had been reluctant to publish his calculus due to fear of controversy and criticism (Newman, 1966).

St. Augustine defined Mathematics as "the study of relationships among quantities, magnitudes and properties, and also of the logical operations by which unknown quantities, magnitudes, and properties may be deduced" "the study of quantity, structure, space and change. Augustine argues that numbers are not conveyed to us by the bodily senses. His argument is that whatever we contact with a bodily sense is proved to be not one but many. "But however, I come to know unity; I have not learned it from bodily senses. Augustine argues that we know the truth of the firm, unbroken rule that the fourth number after 4 is its double, the fifth number after 5 is its double, the double of any number is found to be exactly as far from that number as that number is from the beginning of the series. The Nature of Mathematical Truth there is an argument against the very notion that mathematics is a priori knowledge at all (James,1992).

Ivan (2002), in a very general sense, mathematics can be described as the science of numbers and space. However, mathematics can be more properly regarded as a form of language, developed by people in order to exchange ideas about abstract concepts pertaining to numbers and space. Mathematics is the most economical language for formulating theories in natural sciences. The origins are, however, to a great extent unknown because the beginnings of Mathematics are older than writings. It is usually assumed that early Mathematics in the form of counting arose in response to practical human needs, counting the domestic animals. In a general way, counting may be regarded as the process of matching the objects to be counted with some familiar set of objects such as fingers, toes, pebbles, sticks. Counting as described in this way has also found use in the modern computer-assisted enumeration schemes.

In (500B.c.), Mathematics is a very general sense; Mathematics can be described as the science of numbers and space. However, mathematics can be more properly regarded as a form of language, developed by people in order to exchange ideas about abstract concepts pertaining to numbers and space. Mathematics is also the most economical language for formulating theories in natural sciences. Mathematics is not usually categorized as a natural science; it is a product of an intelligent mind. This could also be restated as that nature, that is, physical, chemical and biological processes, of course, there are also other opinions on the nature of Mathematics, such as that Mathematical objects do exist and Mathematicians simply discover the existing theories.

Furthermore, the enormous usefulness of Mathematics in the natural sciences is something bordering on the mysterious and that there is no rational explanation for it". This sounds like an echo from the times of Pythagoras, who was magically fascinated by Mathematics and believed that "everything is arranged according to number". Moreover, Pythagoras suggested that discoveries were made in connection with their innumerable attempts to solve the following three famous problems; to trisect an arc or an angle, to double the cube, and to square the circle, example to find a square or some other rectilinear figure exactly equal in area to a given circle (Maor, 2007).

In (387 BC), Plato argued that the study of arithmetic has a positive effect on individuals, compelling them to reason about abstract numbers. Plato consistently held to this view, showing indignation at technicians' use of physical arguments to prove results in applied settings. For Plato, Mathematics came to be identical with philosophy for modern thinkers, though they say that it should be studied for the sake of other things. Plato took the position that the objects of Mathematics had an existence of their own, beyond the mind, in the external world. Plato identified clear distinctions between the ideas of the mind and their representations 
perceived in the world by the senses. This caused Plato to draw distinctions between arithmetic the theory of numbers and logistics as the techniques of computation required by businessmen (Ludwing, 1949).

In Aristotle's view, (330 BC), the construction of a mathematical idea comes through idealizations performed by the mathematician as a result of experience with objects. Thus, statements in applied Mathematics are approximations of theorems in pure mathematics. Aristotle attempted to understand mathematical relationships through the collection and classification of empirical results derived from experiments and observations and then by deduction of a system to explain the inherent relationships in the data. Though experimenting himself in biological matters, Descartes rejected input from experimentation and the senses in matters mathematical since it might possibly delude the perceiver. Descartes' consideration of mathematics worked to separate it from the senses. Since the name "Mathematics" means exactly the same as scientific can easily distinguish what relates to Mathematics in any question from that which belongs to the other sciences (Ackrill, 1981).

\subsection{Literature review}

Paul (1939), argued that application of Mathematics in Physics is that the equations representing the laws of motion should be of a simple form. The whole success of the scheme is due to the fact that equations of simple form do seem to work. The physicist is thus provided with a principle of simplicity. The data obtained from rough experiments fits roughly in certain simple equations; this inferring that if the performed experiments are systematically and accurately executed gives data which fits precisely in the equations.

Lehman (1994), assured that the existence of various levels of curriculum integration between Mathematics and sciences showed a fair amount of variability, ranging from correlation coefficient of 0.39 on the original scale 0.89 from the rescaled scores. These relationship indicators can be articulated in an assessment of education quality in Mathematics and science. Furthermore, the reasons for Mathematics and science integration were "to increase students" achievement in both disciplines".

There is a general notion that these two fields are interrelated, where students' ability in Mathematics may positively correlate with ability in Physics (Tuminaro, 2004). In studying Physics, students are faced with solving physical problems describing theoretical models to real world phenomena, especially when using Mathematics. The combination of mathematical operations and conceptual reasoning about physical phenomena in physics, afford the privilege to have a supreme meaning. Thus, an in-depth knowledge of Mathematics is required to effectively cope with the rigour involved in solving problems in Physics (Kuo et al ., 2013).

Mathematics and physics are central in the development of science and technology. The complex nature of Mathematics is attributed by its categorisation into "Pure" and "Applied" Mathematics, where "pure" mathematics does not have any practical purpose but "applied" Mathematics is employed to understand and solve any physical occurring problem. Mathematics is the language of sciences, an abstract language which explains natural phenomena .Traditionally Physics is presented in the form of rules, laws and principles; mathematically elaborated by formulas and equations (Torigoe, 2008).

Bello and Ariyo (2014), conducted a study on Mathematics as determinant of academic performance in Physics at ordinary and higher levels. The study determined the relationship between performance in secondary schools and undergraduate students'. The study employed ex-post-facto and survey research design methods to sample198 students randomly from 6 departments in the Faculty of Science, University of Ibadan. The data collected were analyzed using correlation coefficient, linear regression and percentage. The result revealed that, there is no significant relationship between performance in secondary school and undergraduate students 'but there is a significant relationship between their performance in Mathematics and their attitude to Physics at higher levels.

Large number of education stakeholders believes that teaching through problem-solving plays a central role in the process of effective teaching of Mathematics and Physics. Van (2001) argued that teaching through problem solving requires a teacher to make the atmosphere and the lesson to be more practical oriented. Problem solving is a task or activity that has the potential to provide intellectual challenges for enhancing students understanding, and defining a problem as any task or activity that has no one correct solution, engages students and helps them to make sense of the Mathematics involved, and requires the students to 
justify and explain their methods applied in getting solutions (Cai and Lester, 2010).In terms of the content structure, the relationship seems to be asymmetric between Mathematics and science. "Mathematics teachers can choose to avoid science subjects, except science teachers whom borrow a lot from Mathematics (Frykholm and Meyer, 2002).

Mathematics has been a major influence to pure science subject and has become an integral part of the society in the current world. Science subjects at the ordinary level in Tanzania are among the high-profile subjects. Science subjects are not compulsory for all ordinary level students except Biology. Students in Secondary schools especially in form three classes are allowed to drop some subjects depending on their ability, either to continue with chemistry or chemistry and physics classes where as those non-Science students are allowed to drop Science subjects. The student's decision regarding choice of Science subjects at secondary schools are often made with tiny information and awareness. Students make choice of optional Science subjects with considerable ambiguity, uncertainty and stress (Ndalichako and Komba, 2014). Therefore, this study intended to assess the influence of Mathematics in Physics subject. A case study of secondary schools in Tanzania.

\subsection{Materials and Methods}

The study employed both qualitative and quantitative research approaches. The method allows direct interaction between the researcher and the participants. Patton (1990) points out that a qualitative method permits the study to speculate issues in depth and in detail. The method can produce a wealth of detailed information from a small number of research sites and its cases while quantitative research approach was applied for gathering numerical data. The combination of the two approaches was made purposely in order to offset weaknesses of each other. The research design used is the concurrent triangulation design, which is used when the focus is on confirming, cross-validating, or corroborating findings from a single study. Qualitative and quantitative data are collected concurrently, such that weaknesses of one kind of data are ideally offset by strengths of the other kind. Typically, equal weight is given to the two kinds of data in mixing the findings, analyzed separately, and mixing takes place when the findings are interpreted.

A total of 60 participants were selected through the use of simple random and purposive sampling techniques during gathering of data in the field. The techniques were employed in order to lower the degree of biasness during data collection processes. The science and Mathematics teachers and students in secondary schools were fully participated in data collection. The documentary analysis, questionnaire, and observation were the key devices in collecting data from the field. The collected data were analyzed through the use of Statistical Package for social sciences (SPSS). This enabled a clear interpretation of the numerical values obtained and accelerated a convincing conclusion to be reached.

\subsection{Results and Discussion}

\subsection{Applications of Mathematics subject in physics}

The surveyed participants identified the following 6 main applications of Mathematics in Physics and their detailed explanations.

\subsubsection{Mathematics is a key tool in deriving various formulae}

Understanding formula in physics is not just about learning the mathematical operations. It is about making many connections to stores of knowledge about the physical system; not just at the level of variable definitions but at level of the bases of the mathematical operations and how those operations connect to physical meaning. Expectations that the Mathematics describing a physical system should connect to our intuitive sense about the physical system that can also provide a valuable safety net against possible errors in the calculations and help us make sense of new or unfamiliar equations. This perspective, enhanced by the tools developed recently by cognitive semanticists, should help give us new and deeper insights into the use of Mathematics in Physics and the other sciences including derivation of formulae 40(66.7\%) of the participants mentioned the concept. The application can be demonstrated through considering the equations of motion and its usage in deriving formulae in projectile motion. Illustration, when kicking a ball vertically, one can determine the maximum height through which a ball can reach and the time of flighting. In deriving the formulae one gets $h=\frac{V_{0}^{2} \sin (2 \theta)}{g}$ and $t=\frac{2 V_{0} \sin (\theta)}{g}$ where, $h$ is the maximum height reached by the 
ball, $V_{0}$ is the initial velocity, $\theta$ is the angle made between the resultant and the horizontal line, $g$ is the acceleration due to gravity $\left(g=10 \mathrm{~m} / \mathrm{s}^{2}\right.$ or $\left.\quad g=9.8 \mathrm{~m} / \mathrm{s}^{2}\right)$ and $t$ is the time of flighting.

\subsubsection{Mathematics plays a vital role in taking measurements}

The application of Mathematics in Physics is wide, almost in each field of Physics, Mathematics is applied. $38(63.3 \%)$ of the participants stated that the measurement of temperature, sound, frequency and motions is observed. Now, let us consider the case of Newton's law of cooling, a student can determine the temperature of any cooling body through the use of Newtonian formula expressed as $\theta_{f}=\theta_{S}+\left(\theta_{0}-\theta_{S}\right) e^{-k t}$, where $\theta_{f}$ is the final cooling temperature, $\theta_{S}$ is the temperature of the surrounding environment, $\theta_{0}$ is the initial cooling temperature, $e=2.718, k$ is the constant of cooling and $t$ is the time taken by an object in cooling. An individual might be given numerical values of other parameters except time $t$. In order to get time $t$ " $a$ student is forced to recall formulae transposition lesson which is covered in form two class".

\subsection{Mathematics is applied in calculating distance of moving objects}

A student can determine how fast a rocket must be moving as it escapes the atmosphere for it to escape entirely from the Earth's gravitational field. This is known as escape velocity, and, neglecting the depth of the atmosphere, it clearly needs sufficient initial kinetic energy to climb all the way up the hill. In using this concept, one can compare the potential and kinetic energies eventually the radius of moving object is attained. Thus, $r_{0}=\frac{2 G M}{V_{0}^{2}}$, where $r_{0}$ is the radius of the moving object, $G$ is the universal gravitational constant $\left(G=6.67 \times 10^{-11} \mathrm{Nm}^{2} / \mathrm{kg}^{2}\right), M$ is the mass of the moving body and $V_{0}$ is the escape velocity. The aspect of calculating the distance of moving objects was started by $53(93.3 \%)$ of the participants in a convincingly manner.

\subsubsection{Mathematics is applied in Experiment}

Naturally, most of the things vibrate in a periodic fashion; a simple pendulum is a good demonstration of the idea. About $60(100 \%)$ of the participants showed the necessity of Mathematics on Physical experiments .The demonstration can be done through suspending a mass at the end of a piece of string and allow it to oscillate. The to and fro motion represents a periodic motion called simple harmonic motion. Galileo demonstrated that the time a pendulum takes to swing through small distance depends on the length of the pendulum but not on the mass of the pendulum or size of the arc through which it swings. The other factor which is considered in the periodic motion is, the acceleration due to gravity $\left(g=10 \mathrm{~m} / \mathrm{s}^{2}\right.$ or $\left.\quad g=9.8 \mathrm{~m} / \mathrm{s}^{2}\right)$, on the earth. During experiment, one should not that a long pendulum has a greater period than a shorter pendulum .The guiding formula in doing periodic motion experiments is expressed as $T=2 \pi \sqrt{\frac{l}{g}}$, in determining the acceleration due to gravity, the concept of formulae transposition is applied and eventually $g=\frac{4 \pi^{2} l}{T^{2}}$, where $\pi=3.1428$ and $T$ is the period during oscillations.

\subsubsection{Mathematics is applied in engineering}

With reference to $58(96.7 \%)$ of the participants supposed that Mathematics is an important part of most branches of engineering. Engineers are required to possess skills of solving Mathematical models and interpreting the practical inferences. This is done through the help of software installed in computers. The correct balance between logical solutions and intuition, practice and theory should be maintained in giving out reliable and valid results, which attributes to a convincing conclusion. One among the typical examples in engineering is modelling vibrations of a string in 2 dimensions which is illustrated with a wave equation $\frac{\partial^{2} u}{\partial t^{2}}=c^{2} \frac{\partial^{2} u}{\partial x^{2}}$, where $t$ is the time, $u$ may be the pressure in liquid / gas or displacement along some specific direction of the vibrating solid away from their resting positions, $c$ is the speed of propagation and $x$ is the spatial variable. The wave equation might be linear or non linear, linear equations are easily solved 
through the use of analytical methods but non linear equations are difficult to be solved analytically and hence numerical methods are needed.

\section{1 .6 Mathematics is applied in understanding the natural disasters}

The study of the natural disasters including earthquake, Tsunami and floods, its occurrence needs estimation from various Mathematical fields proclaimed by 37(61.7\%) participants' . The idea can be demonstrated through considering the magnitude of an earthquake which is a number that relates to the amplitude of the earthquake. The magnitudes of the Earthquake are scaled in logarithmic, implying that 1 unit increase in magnitude corresponds to a 10 fold increase in amplitude. Geologists can estimate the true magnitude of an earthquake by means of measuring its effects, this leads to earthquakes appearing to have different magnitudes depending on the method used for estimating the magnitude and the datasets used to make the estimate. At the beginning, the magnitudes of the earthquake were measured by a standard seismograph based on the amplitude of ground motion displacement (Richter Magnitude) defined as a local magnitude, mathematically expressed as

$M L=\log A+2.56 \log D-1.67$, where $\boldsymbol{A}$ is the amplitude measured in a ground motion (in micrometers) and $\boldsymbol{D}$ is the distance from the event (in $\mathrm{km}$ ). This is still used for measuring the magnitude of shallow events at distances less than $\mathbf{6 0 0 ~} \mathbf{~ k m}$ (today called the Local Magnitude). The events with magnitude 8, this scale saturates and gives magnitude estimates that are too small. The earthquakes measured at distances greater than $600 \mathrm{~km}$, the body wave magnitude is used to estimated by using the formula $M b=\log \left(\frac{A}{T}\right)+\delta(D, h)$, where $\mathrm{A}$ is the maximum amplitude (in micrometers)of the $\mathbf{P}$ waves measured at period $\boldsymbol{T}$ (generally about 1second) and $\delta$ is a calibration term (in the range 6-8) that depends on distance from the event $\boldsymbol{D}$ and depth of the event $\boldsymbol{h}$ (tables of $\delta$ are used).

\subsection{The influence of Mathematics in Physics subject}

The perfect measure of linear relationship is correlation which is a bivariate analysis that measures the strength of association between two variables and the direction of the relationship. In terms of the strength of relationship, the value of the correlation coefficient lies between +1 and -1 . A value of \pm 1 indicates a perfect degree of association between the two variables. As the value of the correlation coefficient goes towards 0 , the relationship between the two variables becomes weaker. In the field of research, Pearson correlation, Kendall rank correlation, Spearman correlation and the Point- Biserial correlation are commonly used in measuring degree of association between the two variables. Indeed, Pearson's product moment correlation coefficient is used when both variables being studied are normally distributed while the Spearman's and Kendall's rank correlation coefficients are used when one or both variables are skewed or ordinal and it is robust when extreme values are present. Table 1 below shows the annual examination scores of students in Mathematics and Physics.

Table 1: The annual examination scores of students

\begin{tabular}{|c|c|}
\hline \multicolumn{2}{|c|}{ Continuous assessment tests } \\
\hline \multicolumn{2}{|c|}{ Subjects } \\
\hline Mathematics & Physics \\
\hline 74.00 & 58.00 \\
\hline 66.00 & 79.00 \\
\hline 75.00 & 65.00 \\
\hline 58.00 & 56.00 \\
\hline 66.00 & 61.00 \\
\hline 71.00 & 62.00 \\
\hline 85.00 & 78.00 \\
\hline 80.00 & 71.00 \\
\hline 55.00 & 50.00 \\
\hline 60.00 & 56.00 \\
\hline
\end{tabular}




\begin{tabular}{|c|c|}
\hline 73.00 & 62.00 \\
\hline 52.00 & 59.00 \\
\hline 70.00 & 59.00 \\
\hline 60.00 & 58.00 \\
\hline 82.00 & 64.00 \\
\hline 55.00 & 49.00 \\
\hline 52.00 & 56.00 \\
\hline 71.00 & 65.00 \\
\hline 48.00 & 56.00 \\
\hline 67.00 & 52.00 \\
\hline 52.00 & 69.00 \\
\hline
\end{tabular}

\section{Source: Field data (2018)}

The analysis of the scores in Table 1, on the influence of Mathematics in Physics gives the results depicted on Table 2.

Table 2: Statistical results generated by SPSS (IBM VERSION 25).

\begin{tabular}{|l|l|c|c|}
\hline \multicolumn{2}{|c|}{} & Maths & Physics \\
\hline \hline \multirow{3}{*}{ Maths } & Pearson Correlation & 1.000 & 0.549 \\
\cline { 2 - 4 } & Sig. (2-tailed) & & 0.010 \\
\cline { 2 - 4 } & $\boldsymbol{n}$ & $\mathbf{2 1}$ & $\mathbf{2 1}$ \\
\hline \multirow{3}{*}{ Physics } & Pearson Correlation & 0.549 & 1.000 \\
\cline { 2 - 4 } & Sig. (2-tailed) & 0.010 & $\mathbf{2 1}$ \\
\cline { 2 - 4 } & $\mathbf{n}$ & $\mathbf{2 1}$ & \\
\hline
\end{tabular}

Correlation is significant at the 0.01 level (2-tailed), since the calculated Pearson correlation coefficient is 0.549 , implying that there is statistically very strong positive relationship between Mathematics and Physics. In other words, the influence of Mathematics in Physics subject is huge to the extent that students are encouraged not to drop Mathematics in their earlier classes. A good mastery of Mathematical skills will accelerate the increase of engineers and geologists in various fields. If the number of engineers increases, the government of Tanzania will benefit positively in getting professional personnel for monitoring and supervising various developmental projects.

\subsection{Conclusion and recommendations}

The study assessed the influence of Mathematics in Physics subject by speculating its major applications as discussed in section 4. 1. The identified applications reveal the reality of Mathematics in learning and teaching Physics subject. The education stakeholders are requested to bear their learners systematically in bringing good number of graduates skilled in engineering and other courses. Furthermore, the tested correlation is significant at the $\mathbf{0 . 0 1}$ level (2-tailed), since the calculated Pearson correlation coefficient is 0.549, justifying that there is statistically very strong positive relationship between Mathematics and Physics. In other words, the influence of Mathematics in Physics subject is enormous to the extent that students are encouraged not to drop Mathematics in their earlier classes. This will assist to increase number of Tanzanian engineers and geologists in various sectors for extracting our natural resources. The study recommended that teaching and learning of Mathematics and Physics should be given more weight by instructors in getting competency Tanzanian engineers and geologists for extracting our vast natural resources .Moreover, there is a need for students to be encouraged in learning Mathematics and Physics from lower to higher levels. Indeed, applications of these subjects should be realized during lessons, this will accompany in achieving national goals. 


\section{References}

1. Ackrill, J. (1981). Aristotle the Philosopher. Oxford: Oxford University Press

2. Basson, I. (2002). Physics and Mathematics as Interrelated Fields of Thought Development Using Acceleration as an Example. International Journal of Mathematical Education in Science and Technology, 33 (5), 679-690.

3. Bello, T. and Ariyo, B. (2014). Secondary School Mathematics as Determinant of Academic Performance in University Introductory Physics. Journal of Education and Practice 5(39)

4. Bisanz ,J. (2009). Home Numeracy Experiences and Children's Math Performance in the Early School Years, Canadian Journal of Behavioural Science, Vol. 41, No. 2, 55-66, Canadian Psychological Association, Canada.

5. Black, P. (2002). Working inside the black box: Assessment for Learning in the Classroom. London King's College.

6. Cassels, J. and Johnstone, A. (1985). Words that Matter in Science. London: Royal Society of Chemistry

7. Cleaves, A. (2005). The Formation of Science choices at secondary school. International Journal of Science Education, 27 (4), 471 -486.

8. Cohen, L. and Manion, I. (1994). Research Methods in Education. London: Routledge.

9. Comber, L.and Keeves, J (1993). Science education in the nineteenth century: An Empirical study. IEA studies

10. Covington,V . (1984).The Self-worth Theory of Achievement Motivation. Findings and Implications. The Elementary School Journal, 85 (1), 5-20.

11. Eboda, C. (1974). Some correlate of lower Enrolment in Physics in Western Nigeria.

12. Fencl, H and Scheel, K. (2005). Research and Teaching-engaging students, Journal of college science Teaching.

13. Kuo, E., Hull, M. M., Gupta, A. and Elby, A. (2013). How Students Blend Conceptualand Formal M athematical Reasoning in Solving Physics Problems. ScienceEducation 97, 32-57.

14. Hamilton, M. and Machumu, M. (2010). A Study on Needs Assessment of Tanzania Science Education, Dar es Salaam, ESRF.

15. Itta, S. (1994). Some problems encountered in the teaching of mathematics in secondary schools in Tanzania: A case study of secondary schools in Arusha region. University of Dar es Salaam.

16. James, J. (1992).Augustine Confessions 3 Vols. Oxford: Oxford University Press.

17. Kempa, F. and Dude, K. (1974). Science Interest and Attitude traits in students subsequent to the study of the chemistry at the O-level of general certificate of Education. Journal of Research in Science Teaching. 11 (4) 361-370.

18. Kiboss, K. (2002). Impact of a computer Based physics instruction program of pupils understanding of measurement concepts and methods Associated with school science. Journal of Science Education and Technology, vol 1. No 2.

19. King, B. (2000), 'The role of mathematics in the experimental/theoretical/ computational Trichotomy of chemistry', Foundations of Chemistry, 2, 221-36.

20. Kira, S. (2009). Study on Teachers' Questioning Techniques in Advanced Level Chemistry

21. Lessons Master of Science Education (2nd Ed) Dissertation. University of Dar Es Salaam.

22. Kizito ,M. (2008). Students' preferences on science subjects: Does this Affect their Performance? A case of Udzungwa Secondary School, Iringa. Tanzania.

23. Kothari. R. (2008).Research Methodology Methods and Techniques. New Delhi: New age

24. International $(\mathrm{P})$ ltd.

25. Laeter, J. (2001). Enrolment trends in school science education in Australia. International Journal of Science Education, 23 (5), 487-500.

26. Lowdin, P. (1990). 'Mathematics in chemistry and in mathematical chemistry', Journal of Mathematical Chemistry, 4, 3-14.

27. Ludwig, E. (1949). The Function of Myth in Plato's Philosophy. Journal of History of Ideas. X (4):463-481.

28. Maina, K. (2009). The Analysis of Teaching Chemistry in Ordinary Level Secondary Schools 
29. for Performance Improvement. A Case Study in Coast Region, Master of Education (Science

30. Education) Dissertation, University of Dar es Salaam.

31. Magiri, R. (1997). A study of Relationship Between Attitudes and Achievement in Top Quartile sand Lower Quartiles in Physics among Form Four Students in Imenti Division of Meru District Unpublished med thesis, Kenyatta University.

32. Maor, E. (2007). The Pythagorean Theorem. Princeton: University Press.

33. Masanja, V and Butare ,H. (2010). Increasing Women's Participation in Science, Mathematics and Technology Education and Employment in Africa, Expert group meeting in Gender,

34. Science and Technology, 28 September - 1 October 2010, Paris.

35. Mooney, R. (1981). An approach to Conceptual Difficulties in Physics. New York: Strafford

36. Press.

37. Mushi, P. (1996) Tanzania Secondary School Science Teachers Perception and Reaction to Gender Difference in Performance in Science, UTAFTTI (New Series) Vol. 3 NQ. 2, 1996:91-130.

38. Mvungi, F. (2009). School Based Factors Influencing Science Students' Choice of Teaching

39. Science as a Career: The Case of Government Secondary Schools in Ilala District, Dar

40. es Salaam Region, Master of Education (Science), Dissertation, University of Dar es

41. Salaam.

42. Nasta, K .(2007). Influence of Career Self Efficacy Beliefs on Career Exploration Behaviours, Master of Science in Mental Health Counselling. The State University of New York .New York.

43. Newman, C. (1966). A Brief History of the Postgraduate Medical School.Postgrad Med; 42:738-40.

44. Ndalichako, L. and Komba, A. (2014). Students "Subject Choice in Secondary Schools in Tanzania. A Matter of Students" Ability and Interests or Forced 68 Circumstances? Scientific research. (Retrieved October 2nd, 2015).

45. Orodho, A.and Kombo, P. (2002), Research Methods: Nairobi, Kenyatta University Institute of Open Learning.

46. Osaki, K. (2000). Quality of education in Tanzania: A Focus on Curriculum, Standards and Accountability in schools, Headmasters conference on education 11-12 October, 2000 at Arusha International Conference Centre.

47. Osborne, J. and Simon, S. (2003). Attitude Towards Science: A Review of the Literature and its

48. Implications. International Journal of Science Education, 25 (9), 1049-1079. OutcomeS in

49. Latin America. Paper presented at the "Year 2000 Conference of Early.

50. Pearson, R. (1994). Principle of Maximum Physical Hardness: The Journal of Physical Chemistry, 98, 1989-92.

51. MoE , (2012). Curriculum Planning and Development Division: Ministry of Education (MoE)Singapore.

52. Rogers, K. and Ford, M. (1997). Attitude and Performance: Journal of science and Technology.

53. Sichizya, F. (1997).Teaching and Learning Mathematics in Tanzanian Secondary Schools. A paper Presented in the Symposium in Mathematics Modelling Workshop on Mathematics Education, Arusha.

54. South African journal of Education, (2006). Factors Associated with High School learner's poor Performance: A Spotlight on Mathematics and Physical Science: Durban.

55. Tanzania Commission for Science and Technology (COSTECH), (2008). Causes and Solutions for Dismal Performance of Science Subjects in Secondary Schools in Tanzania.

56. Torigoe, E. (2008). "What kind of Math matter? A study of the Relationship between Mathematical Ability and success in Physics. Doctoral dissertation". University of Illinois at Urbana-Champaign, Urbana.

57. Tuminaro, J. (2004). A Cognitive Framework for Analyzing and Describing Introductory Students' Use and Understanding of Mathematics in Physics, Ph.D. Thesis. University of Maryland.

58. Thomas. A and Pedersen. E. (2003), reforming elementary science teacher preparation, What about extent teaching beliefs? School science and Mathematics. 